\title{
Muslim women choice for gender of obstetricians and gynecologist in Turkey ${ }^{1}$
}

\author{
Meltem Demirgöz Bal ${ }^{2}$ \\ Sema Dereli Y1lmaz ${ }^{3}$ \\ Nezihe Kizılkaya Beji ${ }^{4}$ \\ Seyfettin Uludağ $\breve{g}^{5}$
}

\begin{abstract}
Objective: It would generally be thought of that the Muslim women especially preferred female obstetricians/gynecologists (ob/gyn). The aim of this study is to investigate the gender preference of Turkish Muslim women regarding ob/gyn, and identify other features that affect their choice.

Methods: In this study it has been included 710 women attending to gynecology and antenatal clinics and they have been asked to complete a survey questionnaire containing 16 items and requiring opinion on whether they want to be examined medically by a female or male ob/gyn and have no preference. The questions have also contained the reasons for the stated preference.

Results: Of all participants, $230(32,3 \%)$ preferred to have a female ob/gyn, 380(53,5\%) declared no preference, and $100(14,2 \%)$ preferred to have a male ob/gyn. The reasons for female preference were i) having a very good communication $(36 \%)$, ii) embarrassment $(32 \%)$ and iii) feeling comfortable with female ob/gyn (27\%). Surprisingly, only $5 \%$ women responded that the religious orders are important in their preference. The participants who have larger family, lower level of education, lower income, higher unemployment, parity of 4 and over, and first gynecological examination, have preferred female ob/gyn $(p<0,05)$. One hundred women who preferred to be examined by a male doctor stated that the reasons for their preference were i) surgical skills (45\%), ii) even tempered (35\%) and iii) understanding problems better $(20 \%)$.

Conclusions: The majority of women have expressed no preference about gender of their $\mathrm{ob} /$ gyn, but a significant proportion of the remainder would prefer to be examined by a female doctor when they have been given the choice. However the religious effects on female ob/gyn preference have been found much less than the cultural effects.
\end{abstract}

Keywords: Obstetrician/gynecologist; Gender choice; Turkish women; Muslim; Women health

\footnotetext{
1 4.International Congress on Medical Ethics and Law, Oral Presentation, 12-15 November 2013

2 Assist. Prof. Dr., Karamanoglu Mehmetbey University, Health College, Karaman. meltemdemirgoz@gmail.com

3 Assist. Prof. Dr., Selçuk University, Health Sciences Faculty, Department of Midwifery, Konya. syilmaz33@gmail.com

${ }_{4}$ Prof. Dr., Istanbul University, Florence Nightingale Nursing Faculty, Department of Obstetric and Gynecology Nursing, nezihebeji@yahoo.com

5 Prof. Dr., Istanbul University, Cerrahpasa Health Faculty, Department of Gynecologic and Obstetric s.uludag@istanbul.edu.tr.
} 
Demirgöz Bal, M., Dereli Yılmaz, S., Kızllkaya Beji, N., \& Uludağ, S. (2014). Muslim women choice for gender of obstetricians and gynecologist in Turkey. International Journal of Human Sciences, 11(2), 64-73. doi: $10.14687 /$ ijhs.v11i2.2873

\section{INTRODUCTION}

Many studies which are related to the choice of women for the obstetricians/gynecologists (ob/gyn) gender, have been carried out in the past. Although there are studies supporting the significance of choosing ob/gyn gender, the contradictory studies are also present in literature. The major differences in these studies originate from various socio, economic, religious, traditional and cultural factors (Plunkett, Kohli, \& Milad, 2002; Thompson, \& Nussbaum, 2000; Makam, Mallappa Saroja, \& Edwards, 2010; Mavis, Vasilenko, Schnuth, Marshall, \& Jeffs, 2005; Schmittdiel, Selby, Grumbach, \& Quesenberry, 1999; Chandler, Chandler, \& Dabbs, 2000; Roter, \& Hall 2001; Lafta, 2006). In 2005, Rizk et al. carried out a survey on gender preference and the factors effecting on the gynecologist/ obstetrician preference in the United Arab Emirates (UAE) in which the majority of participants $(95 \%)$ were Muslims. They found that the gender was ranked as one of the most important factors for selection of women, regardless of other relevant factors (Rizk et al. 2005). Bashour et al. reported that more than $85 \%$ of Syrian preferred their obstetrician to be a female person (Bashour, \& Abdulsalam 2005). Lafta et al. found that $74 \%$ of Iraqi women patients preferred female gynecologists, $8 \%$ preferred male gynecologists and 18\% had no gender preference (Lafta 2006).

Islamic teologists have reported that the Muslim women should take medical services from women $\mathrm{ob} /$ gyn according to the general principles of Quran unless compulsory. So it is not appropriate for Muslim women to be examined by a male doctor particularly in consultation for necessary examination of the genitalia (Sechzer, 2004).

Turkey is a mostly Muslim-populated, culturally rich, but the only secular country in the region. Due to this secular pattern, the study about the choice of women for ob/gyn gender in Turkey and the factors affecting the gender preference for ob/gyn is of significant importance to contribute to the literature.

\section{MATERIALS \& METHODS}

This cross-sectional and descriptive study has been performed in Istanbul. Istanbul is the largest city and has the most nomadic population in Turkey. Because of this, Istanbul has more diversity than the other cities in Turkey. The study was approved by the Institutional Review Board of Medical Faculty. This study has been conducted between the dates of February 2013 and June 2013, among the women who volunteered to participate in the survey and have been appropriate for the criteria. The study has been carried out for patients who applied to antenatal or gynecologic departments. The patients have been selected to reduce a potential practice-setting bias, after having antenatal or gynecologic care. The data have been collected with a questionnaire produced 
Demirgöz Bal, M., Dereli Yılmaz, S., Kızılkaya Beji, N., \& Uludağ, S. (2014). Muslim women choice for gender of obstetricians and gynecologist in Turkey. International Journal of Human Sciences, 11(2), 64-73. doi: $10.14687 /$ ijhs.v11i2.2873

by the researcher. The questionnaire has been filled in waiting room. The participants have been asked why they selected the corresponding gender for their examiner. The women have responded to this question by selecting more than one choice in the questionnaire.

Of the total 745 women, 35 refused enrollment and the remaining (eligible) 710 women gave their oral consent to participate in the study. There were two parts of questionnaire: The first part of the questionnaire had the basic socio-demographic data (such as; age, educational level, marital status, family status, income level, employment status), in the second part, the women were asked about the obstetric/gynecologic histories and their gender preferences and the reasons.

The Statistical Package for Social Sciences (SPSS) was used for the statistical analysis of the data. The findings were evaluated with a confidence interval of $95 \%$, and $\mathrm{p}<0.05$ was accepted as a significance proportion.

\section{RESULTS}

The cross sectional study sample consisted of 710 ( $95 \%$ response rate) out of 745 consecutive patients attending to the antenatal or gynecology outpatient departments. The participants had the ages between 17 and 58 and were all Muslim. The demographic data of all participants are shown in Table 1. In this study the little family means that it has only the mother/father and children while the large family has the mother/father, children, grandfather, and grandmother etc. The income level of participants has been based on their declaration. The income level has been classified into two groups; one of them is low income that means if the expenses are higher than income, otherwise it is classified as a sufficient income.

While no preference about ob/gyn gender choice have been declared by $380(53,5 \%)$ patients of all participants, $230(32,3 \%)$ patients preferred a female ob/gyn and $100(14,2 \%)$ patients preferred a male ob/gyn.

In order to perform the data analysis, the factors that may have affected ob/gyn gender preference by women, have been summarized in Table 2 .

The women who preferred female ob/gyn, stated that they had very good communication with female ob/gyn (36\%), much less embarrassment (32\%) and much more felt as comfortable $(27 \%)$. Surprisingly, only $5 \%$ of women responded that the religious orders are important for their selection.

In this study the majority of the women preferred male ob/gyn for surgical skills (urogynecology, gynecologic oncology, operative laparoscopy etc) (45\%), even tempered (35\%) and understanding the problems better $(20 \%)$, respectively. 
Demirgöz Bal, M., Dereli Yılmaz, S., Kızılkaya Beji, N., \& Uludağ, S. (2014). Muslim women choice for gender of obstetricians and gynecologist in Turkey. International Journal of Human Sciences, 11(2), 64-73. doi: $10.14687 /$ ijhs.v11i2.2873

\section{DISCUSSION}

The awareness of women in Turkey on women's health is getting more improved than before, and thus, this improvement influences the selection of ob/gyn gender. It would be considered that especially the Muslim women preferred female ob/gyn. Contrary to this, in the present study; it has been shown that the half of the patients have given no importance for ob/gyn gender selection when they had obstetric and gynecologic problems. Similar results were found in studies performed in Chicago (Plunkett, Kohli, \& Milad, 2002), California (Thompson, \& Nussbaum, 2000), (Makam, Mallappa Saroja, \& Edwards, 2010), Michigan (Mavis, Vasilenko, Schnuth, Marshall, \& Jeffs, 2005), New York (Howell, Gardiner, \& Concato 2002), and Savannah (Childs, Friedman, Schwartz, Johnson, \& Royek 2005) although some others showed opposed findings (Schmittdiel, Selby, Grumbach, \& Quesenberry, 1999; Chandler, Chandler, \& Dabbs, 2000; Roter, \& Hall 2001; Lafta, 2006; Zuckerman, Navizedeh, Feldman, McCalla, \& Minkoff, 2002; Ekeroma, \& Harillal 2003; Baskett, 2002; Fisher, Bryan, Dervaitis, Silcox, \& Kohn 2002). In contrary to the results of this study, in many studies performed in other Muslim Countries, the women selected mainly female ob/gyn due to religious factors (Lafta 2006; Rizk, El-Zubeir, AlDhaheri, Al-Mansouri, \& Al-Jenaibi, 2005; Bashour, \& Abdulsalam 2005). Muslim women believe that they should be examined for their obstetric and gynecologic problems by the same gender (women) and Muslim ob/gyn (Scheinberg, 2006). The instructions for Kuwaiti doctors are close to the precautions listed so far: during a vaginal examination, the patient should remain covered as for as possible by a sheet; if the patient is being examined by a male doctor, a nurse or other women must be present. During the labor, the pregnant woman may instinctively grip the doctor's hand or arm to obtain a psychological comfort. However, the doctor should not encourage such a behavior but be replaced by a nurse (Atighetchi, 2007). Muslim women, especially in the traditional countries, are reluctant to be examined by a man even in the presence of another woman during the examination. A survey at the gynecological clinics of two major hospitals in Riyadh 500 female patients confirmed this trend (Eiad et al 2004). Among the reasons to justify the preference of women doctors during the examination, the religion was the main reason for $69 \%$ of the Saudi Arabians against 50\% of the non Saudi Arabians (Al-Shammari, Jarallah, \& Felimban, 1997). The importance of the religious factor is obvious in a very recent survey on the behavior of 508 patients of the obstetric and gynecologic department in UAE. In this case, 86,4\% preferred a women doctor, 12 mentioned no particular preference, whilst 1.6 preferred a male gynecologist (Rizk et al. 2004). However, in the study done with non-Muslim women by Amir et.al, (2012), the secular, religious and ultra-orthodox women preferred a female gynecologist in the percentage of $52 \%, 69 \%$ 
Demirgöz Bal, M., Dereli Yılmaz, S., Kızılkaya Beji, N., \& Uludağ, S. (2014). Muslim women choice for gender of obstetricians and gynecologist in Turkey. International Journal of Human Sciences, 11(2), 64-73. doi: $10.14687 /$ ijhs.v11i2.2873

and 93\%, respectively (Amir, Tibi, Groutz, Amit, \& Azemi, 2012). Although this study has been carried out with Muslim women, it has been found that the religious factors are not very important $(n=27)$ in the ob/gyn gender choice. The probable reason of this finding is that Turkey is a unique secular country, even though most of the population is Muslim.

In many studies it was found out that the women selected the ob/gyn according to not only the gender factor but also the other factors (Plunkett, Kohli, \& Milad, 2002; Chandler, Chandler, \& Dabbs, 2000; Sechzer 2004; Childs, Friedman, Schwartz, Johnson, \& Royek, 2005; Johnson, Schnatz, Kelsey, \& Ohannessian, 2005; Piper, Shvarts, \& Lurie 2008; Hall, Irish, \& Roter 1994; Roter, Lipkin, \& Korsgaard, 1991). The results in this study showed that the women who had better communicative skills, more comfortable and more embarrassment, selected much more female $\mathrm{ob} /$ gyn than male ob/gyn. These findings are very similar to those indicated in most other studies (Chandler, Chandler, \& Dabbs, 2000; Howell, Gardiner, \& Concato, 2002; Ekeroma, \& Harillal, 2003; Roter, \& Hall, 2001; Elstad, 1994; Franks, \& Bertakis, 2003). In another study carried out with Muslim women, it was shown that the women who had embarrassment during intimate examination $(89,1 \%)$, religious attitudes $(74.3 \%)$, cultural objections $(45.3 \%)$ and were reluctance to discuss sensitive and confidential issues (68,8\%), also selected female ob/gyn in a higher rate (Rizk, El-Zubeir, Al-Dhaheri, Al-Mansouri, \& Al-Jenaibi, 2005). The orthodox Jewish women, who were more comfortable and had less embarrassment attitude, also selected female ob/gyn (Scheinberg, 2006). In the studies performed by Lafta et al. in Iraq and by Rizk et al. in United Arabic Emirates, female ob/gyn were preferred due to better communicative skills and feeling relaxed by women patients, and male ob/gyn due to better surgical skills. The results are compatible with those in our study (Lafta, 2006; Rizk, El-Zubeir, Al-Dhaheri, Al-Mansouri, \& AlJenaibi, 2005). In a recent study by Janssenet.al. it was found out that the women ob/gyn have been chosen much more since they had patient centered communication (Janssen \& Lagro-Janssen 2012).

Our study revealed that the male ob/gyn has been needed for obstetric or gynecological problems of women when the participants were looking for more surgical skills. Interestingly in different cultures similar results were obtained (Lafta , 2006; Rizk, El-Zubeir, Al-Dhaheri, Al-Mansouri, \& Al-Jenaibi 2005; Childs, Friedman, Schwartz, Johnson, \& Royek, 2005; Amir, Tibi, Groutz, Amit, \& Azem, 2012; Johnson, Schnatz, Kelsey, \& Ohannessian 2005; Janssen \&, Lagro-Janssen 2012) The correlation is not however clear between the surgical skills and masculinity. 
Demirgöz Bal, M., Dereli Yılmaz, S., Kızılkaya Beji, N., \& Uludağ, S. (2014). Muslim women choice for gender of obstetricians and gynecologist in Turkey. International Journal of Human Sciences, 11(2), 64-73. doi: $10.14687 /$ ijhs.v11i2.2873

Most of the women who preferred male ob/gyn thought of that male ob/gyn understands much better than women ob/gyn. Parallel to the results of this study, in Dulmen et al, the male gynecologists used significantly more instruments and male gynecologists asked significantly more medical questions compared with female gynecologists (van Dulmen \&Bensing 2000). In addition, in the study of Makam et.al, all women who preferred male ob/gyn, noted that male ob/gyn understood them much better than female ob/gyn Mavis, Vasilenko, Schnuth, Marshall, \& Jeffs 2005).

Another factor affecting the preference of male ob/gyn has been the even-tempered behaviors of male ob/gyn. In our opinion the basic probable reason of this factor could be that there is a patriarchal family pattern in Turkey. In patriarchal family pattern, the male ob/gyn can be much even-tempered in risky conditions.

We have also found that the socio-cultural factors play an important role in the gender selection. In this study the participants who had larger family, lower level of education, lower income, higher unemployment and parity of 4 and over, preferred female ob/gyn. In a study performed with 6000 women, a significant correlation was found between the low level of income and the choice of female ob/gyn (Schmittdiel, Selby, Grumbach, \& Quesenberry 1999). In another study, the women from families with low income level and preferring female ob/gyn were found not to be much volunteer and shown to be resistant to pelvic examination (Haar, Halitsky, \& Stricker 1975). In a similar way, the women unemployed and from families with low income level, also preferred female ob/gyn more than those in the current study. In addition, a significant correlation was found between the choice of female ob/gyn, and low level of education, high parity, and large family. The findings in this study have been consistent with those in literature (Lafta, 2006; Rizk, El-Zubeir, Al-Dhaheri, Al-Mansouri, \& Al-Jenaibi 2005). In the present study the fourteen percentages of participants were coming from large families. The source of the reason why women preferred female ob/gyn at a higher rate in large families may be from the pressure coming from the elder people who had low level of education.

It has also been obtained that the previous experiences of women had significance effect on the ob/gyn gender selection (Childs, Friedman, Schwartz, Johnson, \& Royek, 2005). We have found that the patients, who were examined by a female ob/gyn at their gynecologic examination with a female $\mathrm{ob} /$ gyn, were more likely to prefer a female ob/gyn. 
Demirgöz Bal, M., Dereli Yılmaz, S., Kızılkaya Beji, N., \& Uludağ, S. (2014). Muslim women choice for gender of obstetricians and gynecologist in Turkey. International Journal of Human Sciences, 11(2), 64-73. doi: $10.14687 /$ ijhs.v11i2.2873

\section{CONCLUSIONS}

Consequently, half of the women in the current study suggested that they preferred no ob/gyn gender. The fact that most of the Turkish populations are based on Islamic-origin has led to no increase in the choice of female ob/gyn. The selection of female ob/gyn is just considered to arise from socio-cultural reasons, rather than religious ones. The gender of physicians is considered not to constitute a barrier in the treatment of women. The findings obtained in the current study indicate also that the skills of ob/gyn, rather than their gender, play a key role in their selection.

The limitation of this study has been applied one center hospital. The generalizability of the study is large sample.

\section{Current knowledge on the subject}

- It would generally be thought of that especially the Muslim women preferred female ob/gyn.

- Islamic teologists have reported that the Muslim women should take medical services from women $\mathrm{ob} /$ gyn according to the general principles of Quran unless compulsory.

-Turkey is a mostly Muslim-populated, culturally rich, but the only secular country in the region.

\section{What does this study add?}

-Most of the Turkish populations are based on Islamic-origin and this has led to no increase in the choice of female ob/gyn.

- The skills of ob/gyn, rather than their gender, play a key role in selection.

- The selection of female ob/gyn is just considered to arise from socio-cultural reasons, rather than religious ones.

The authors declare that they have no conflict of interest. They also indicate that they had no financial relationship with the organization that sponsored the research. The study was approved by the Institutional Review Board Medical Faculty.

\section{REFERENCES}

1. Plunkett, B,A., Kohli, P., \& Milad, M,P. (2002). The importance of physician gender in the selection of an obstetrician or gynecologist. American Journal of Obstetrics and Gynecology, 186(5),926-8. doi.org/10.1067/mob.2002.123401

2. Thompson, M., \& Nussbaum, R. (2000). An HMO survey on mass customization of healthcare delivery for women. Womens Health Issues, 10(1),10-9. doi.org/10.1016/S1049-3867(99)00037-7

3. Makam, A., Mallappa Saroja, C,S., \& Edwards, G. (2010). Do women seeking care from obstetrician-gynaecologists prefer to see a female or a male doctor? Archives of Gynecology and Obstetrics, 281(3),443-7. doi:10.1007/s00404-009-1199-5 
Demirgöz Bal, M., Dereli Yılmaz, S., Kızllkaya Beji, N., \& Uludağ, S. (2014). Muslim women choice for gender of obstetricians and gynecologist in Turkey. International Journal of Human Sciences, 11(2), 64-73. doi: $10.14687 /$ ijhs.v11i2.2873

4. Mavis, B., Vasilenko, P., Schnuth, R., Marshall, J., \& Jeffs, M.C. (2005). Female patients' preferences related to interpersonal communications, clinical competence and gender when selecting a physician. Academic Medicine,80(12),1159-65. doi: 00001888-200512000-00022.

5. Schmittdiel, J., Selby, J,V., Grumbach, K., Quesenberry, C.P. Jr. (1999). Women’s provider preferences for basic gynecology care in a large health maintenance organization. Journal of Womens Health \& Gender Based Medicine, 8(6):825-33. doi:10.1089/152460999319147

6. Chandler, P,J., Chandler, C., \& Dabbs, M,L. (2000). Provider gender preference in obstetrics and gynecology: a military population. Military Medicine, 165(12),938-40.

7. Roter, D,L., \& Hall, J,A. (2001). How physician gender shapes the communication and evaluation of medical care. Mayo Clinic Proceding, 76(7),673-6.

8. Lafta, R,K. (2006). Practitioner gender preference among gynecologic patients in Iraq. Health Care Women International, 27(2):125-30. doi:10.1080/07399330500457903

9. Rizk, D.E., El-Zubeir, M,A., Al-Dhaheri, A,M., Al-Mansouri, F,R., \& Al-Jenaibi, H,S. (2005). Determinants of women's choice of their obstetrician and gynecologist provider in the UAE. Acta Obstet Gynecol Scand 84(1):48-53. DOI: 10.1111/j.0001-6349.2005.00705.x

10.Bashour, H., \& Abdulsalam, A. (2005). Syrian women s preference for birth attendant and birth place. Birth 32(1),20-6. doi: 10.1111/j.0730-7659.2005.00333.

11. Sechzer, J,A. (2004). Islam and woman: where tradition meets modernity. History and interpretations of Islamic women's status. Sex Roles 51,:263-72. doi: 10.1023/B:SERS.0000046610.16101.e0

12.Howell, E,A., Gardiner, B., \& Concato, J. (2002). Do women prefer female obstetricians? Obstetrics and Gynecology, 99(6),1031-5.

13.Childs, A,J., Friedman, W,H., Schwartz, M,P., Johnson, M., \& Royek, A.B. (2005). Patients' Sex Preferences in Selection of Gynecologists and Surgeons. Southern Medical Journal 98(4),405-8.

14.Zuckerman, M., Navizedeh, N., Feldman, J., McCalla, S., \& Minkoff, H. (2002). Determinants of women's choice of obstetrician/gynecologist. Journal of Womens Health \& Gender Based Medicine, 11(2),175-80. doi:10.1089/152460902753645317.

15.Ekeroma, A., \& Harillal, M. (2003). Women's choice in the gender and ethnicity of her obstetrician and gynecologist. The Austrian and New Zealand Obstetrics \& Gynaecology, 43(5),354-9. doi: 10.1046/j.0004-8666.2003.00098.x

16.Baskett, T,F. (2002). What women want: don't call us clients, and we prefer female doctors. Journal of Obstetrics \& Gynaecol Canada, 24(7),572-4.

17.Fisher, W,A., Bryan, A., Dervaitis, K.L., Silcox, J., \& Kohn, H. (2002). It ain't necessarily so: most women do not strongly prefer female obstetrician-gynaecologists. Journal of Obstetrics \& Gynaecol Canada, 24(11),885-8.

18.Scheinberg, A,C. (2006). Modesty and healthcare for women. understanding cultural sensitivities. Community Oncology, 3, 443-6.

19. Atighetchi, D. (2007). Islamic Bioethics: Problems and Perspectives: Problems and Perspectives.

Springer. The

Netherlans, 43-45.

20. Eiad, A., Nasser, A., Doha, M,B., Al Nour, Mohammed, A,B., Saleh, A., Hamed, A., Osman, A., \& Issa, A,M. (1994). The impact of the doctors gender on the doctor-patient relationship in a Saudi obstetric and gynaecology clinic. Saudian Medical Journal, 15(6), 450-455.

21. Al-Shammari, S., Jarallah, J,S., \& Felimban, F. (1997). Long-term care experience in Saudi Arabia. Social Science \& Medicine, 44(5),693-7. doi.org/10.1016/S0277-9536(96)00196-7

22.Amir, H., Tibi, Y., Groutz, A., Amit, A., \& Azem, F. (2012). Unpredicted gender preference of obstetricians and gynecologists by Muslim Israeli- Arab women. Patient Education Counseling, 86(2), 259-63. doi: 10.1016/j.pec.2011.05.016. 
Demirgöz Bal, M., Dereli Yılmaz, S., Kızılkaya Beji, N., \& Uludağ, S. (2014). Muslim women choice for gender of obstetricians and gynecologist in Turkey. International Journal of Human Sciences, 11(2), 64-73. doi: $10.14687 /$ ijhs.v11i2.2873

23.Johnson, A,M., Schnatz, P,F., Kelsey, A,M., \& Ohannessian, C,M. (2005). Do women prefer care from female or male obstetrician-gynecologists? A study of patient gender preference. The Journal of The American Osteopathic Association, 105(8),369-79.

24. Piper, I., Shvarts, S., \& Lurie, S. (2008). Women's preferences for their gynecologist or obstetrician. Patient Educ Couns, 72(1),109-14. doi.org/10.1016/j.pec.2008.02.004

25.Hall, J,A., Irish, J,T., Roter, D,L., Ehrlich, C,M., \& Miller, L.H. (1994). Gender in medical encounters: an analysis of physician and patient communication in a primary setting. Health Psychology, 13(5),384-92. doi: 10.1037/0278-6133.13.5.384

26.Roter, D,L., Lipkin, M., Korsgaard, A. (1991). Sex differences in patients' and physicians' communication during

primary medical visits. Medical Care, 29(11),1083-93.

27.Roter, D.L., Hall, J,A. (2001). How physician gender shapes the communication and evaluation of medical care. Mayo Clinic Procedings, 76(7),673-6.

28.Elstad, J,I. (1994). Women's priorities regarding physician behavior and their preference for a female physician. Women Health, 21(4),1-19. doi: 10.1300/J013r21n04_01

29.Franks, P., Bertakis, K,D. (2003). Physician gender, patient gender, and primary care. Journal of Womens Health (Larchmt, 12(1),73-80. doi10.1089/154099903321154167.

30.Janssen, S,M., \& Lagro-Janssen, A,L. (2012). Physician's gender, communication style, patient preferences and patient satisfaction in gynecology and obstetrics: a systematic review. Patient Education Counseling, 89(2), 221-6. doi: 10.1016/j.pec.2012.06.034.

31.Haar, E., Halitsky, V., \& Stricker, G. (1975). Factors related to the preference for a female gynecologist. Medical Care, 13(9),782-90.

32.van Dulmen, A,M., \& Bensing, J,M. (2000). Gender differences in gynecologist communication. Women Health,30(3),49-61. Doi: 10.1300/J013v30n03_04 
Demirgöz Bal, M., Dereli Yılmaz, S., Kızılkaya Beji, N., \& Uludağ, S. (2014). Muslim women choice for gender of obstetricians and gynecologist in Turkey. International Journal of Human Sciences, 11(2), 64-73. doi: $10.14687 /$ ijhs.v11i2.2873

\section{Appendix 1: Tables}

Table 1. Demographic data of 710 women participated in the study

Characteristics

Marital Status

Single

Married

Widow

Family Status

Little Family

Large Family

Educational Level

Low Education ( $\leq 8$ years)

High Education ( $\geq 9$ years)

Employment

Employed

Unemployed (housewives)

Income Level

Low Income

Sufficient Income
Numbers (n)

113

579

18

610

100

347

363

209

501

325

385
Percentage $(\%)$

16

82

2

86

14

49

51

30

70

46

54

Table 2. Comparison of data for Ob/Gyn Gender Choice*

Female $n=230 \quad$ Male $n=100 \quad$ No choice $n=380 \quad p$ value

\begin{tabular}{|c|c|c|c|c|}
\hline Family Type & 181 & & & \\
\hline Little Family & 49 & 95 & 334 & 0,05 \\
\hline Large Family & & 5 & 46 & \\
\hline Education Level & 141 & & & \\
\hline Low Level of Education & 89 & 33 & 173 & 0,05 \\
\hline High Level of Education & & 67 & 207 & \\
\hline Marital Status & 32 & & & \\
\hline Single & 198 & 9 & 72 & 0,52 \\
\hline Married/Widow & & 91 & 308 & \\
\hline Income Level & 123 & & & \\
\hline Low Income & 107 & 50 & 152 & 0,02 \\
\hline Sufficient Income & & 50 & 228 & \\
\hline Employment & 54 & & & \\
\hline Employed & 176 & 43 & 112 & 0,05 \\
\hline Unemployed & & 57 & 268 & \\
\hline Parity & 123 & & & \\
\hline$\leq 3$ & 75 & 65 & 197 & 0,05 \\
\hline$\geq 4$ & & 26 & 111 & \\
\hline $\begin{array}{l}\text { First } \\
\text { examination }\end{array}$ & & & & \\
\hline Female & 30 & 5 & 14 & \\
\hline Male & & 95 & 366 & 0,05 \\
\hline
\end{tabular}

* chi-square test 